\title{
AS FRONTEIRAS PSICOLÓGICAS ENTRE VIOLÊNCIA, LUTA E BRINCADEIRA: AS TRANSIÇÕES FENOMENOLÓGICAS NA PRÁTICA DA CAPOEIRA
}

\author{
PSYCHOLOGICAL BARRIERS BETWEEN VIOLENCE, FIGHT AND GAME: PHE- \\ NOMENOLOGICAL TRANSITIONS IN THE PRACTICE OF CAPOEIRA
}

FRONTERAS PSICOLÓGICAS ENTRE JUEGO, LUCHA Y LA VIOLENCIA: LAS TRANSICIONES FENOMENOLOGICAS EN LA PRÁCTICA DE LA CAPOEIRA

\section{Fernando de Melo*, Cristiano Roque Antunes Barreira*}

Palavras-chave

Capoeira.

Fenomenologia.

Lutas.

Brincadeiras.

Jogos.

Resumo: Por meio de relatos de capoeiristas entrevistados, visou-se compreender como se dão as experiências vividas nesta prática corporal no trânsito psicológico entre brincadeira, luta e briga. A arqueologia fenomenológica das culturas foi o referencial metodológico utilizado. Três categorias descrevem essencialmente como brincadeira, luta e briga ocorrem propriamente na capoeira: alegria de jogar; jogo da cumplicidade; a negação do jogo. Já os elementos essenciais das transições aparecem em duas categorias: jogo de prudências e jogo duro - orientadas afetivamente pela dinâmica entre abrandamento e intensificação combativa. Confere-se que a intensificação combativa pode tanto acarretar em violência como ocasionar o cultivo do espírito de luta, possibilitando condições existenciais para o autocontrole dos capoeiristas.

Keywords

Capoeira. Phenomenology. Fights.

Games.

Palabras clave

Capoeira. Fenomenología. Luchas. Juegos.
Abstract: The aim of this research is to understand experiences of Capoeira practitioners in the psychological transit between game, fight and quarrels, based on their own accounts. The methodological framework used was the phenomenological archeology of cultures. Three categories essentially describe how game, fight and quarrels really happen in Capoeira: the joy of playing; the game of complicity, and the denial of game. Moreover, the essential elements of transitions appear in two groups: game of prudences and tough game - emotionally guided by the dynamics between slowdown and combative intensification. Combative intensification is found to result either in violence or in the development of the fighting spirit, providing existential conditions for capoeira practitioners' self-control.

Resumen: A través de relatos de capoeiristas entrevistados, buscamos comprender cómo transcurren las experiencias vividas en esta práctica corporal en el tránsito psicológico entre juego, lucha y pelea. La arqueología fenomenológica de las culturas fue el referente metodológico utilizado. Tres categorías describen esencialmente cómo ocurren el juego, la lucha y la pelea en la capoeira: alegría de jugar; juego de la complicidad; la negación del juego. A su vez, los elementos esenciales de las transiciones aparecen en dos categorías -juego de prudencias; juego duro- orientadas afectivamente por la dinámica entre suavización e intensificación combativa. Se constata que la intensificación combativa puede tanto derivar en violencia como ocasionar el cultivo del espíritu de lucha, posibilitando condiciones existenciales para el autocontrol de los capoeiristas.
* Universidade de São Paulo (USP). Ribeirão Preto, SP, Brasil. E-mail: fernando2.melo@outlook.com; crisroba@gmail.com

Recebido em: 07-04-2014 Aprovado em: 13-11-2014 (c) (1) (8) Licence 


\section{INTRODUÇÃO}

A capoeira é uma prática corporal constituída de modo multifacetado, tanto no que se refere à capacidade criativa de realizar movimentos, quanto na sua forma de manifestação como dança, luta, música e jogo (VALÉRIO; BARREIRA, 2012). Essa arte, já enraizada e conhecida como elemento da cultura brasileira, aparece cada vez mais atraente, ampliando 0 público de praticantes. Atualmente a capoeira tem alcance mundial, tornando-se uma prática cultural em processo de internacionalização, agregando e recebendo novos sentidos.

De acordo com Hébert (2011), as lutas em geral promovem virtudes como confiança, autoestima e autocontrole, podendo ser úteis e instrumentalizadas em diferentes situações de atenção psicossocial. Na mesma direção, Reis (2010) entende que a capoeira desenvolve uma qualidade de convívio social e de bem-estar que permite o respeito e a consideração nas relações pessoais. 0 interesse pela educação e formação das pessoas nos esportes de combate e artes marciais é confirmado pela literatura (BERTAZZOLI; ALVES; AMARAL, 2008; TRUSZ; NUNES, 2007; BARREIRA, 2012, 2013a, 2013b; VALÉRIO; BARREIRA, 2012). Com essas colocações iniciais, levantam-se questões na linha problematizada por Barreira (2013b): a prática da capoeira sempre corresponde exclusivamente a ações virtuosas? E quanto ao fato de que, como uma luta, a capoeira tangencia a violência, podendo até misturar-se à mesma?

Para a investigação do combate na capoeira assumiu-se como base a descrição de três diferentes maneiras de se combater cujos contornos fenomenológicos já foram investigados (BARREIRA, 2010, 2013b): a brincadeira de combate, a luta e a briga. A briga com ataque físico acontece como um processo de coisificação do outro, ocorrendo a prevalência motivacional da hostilidade e da força violenta. A luta faz-se como um combate com disposição mútua, procurando limitar os movimentos do adversário, utilizando recursos corporais que não são essencialmente hostis. Quanto à brincadeira de combate, ocorre um aspecto motivacional lúdico, onde os movimentos não obedecem a um sentido de disputa determinada, mas à graça e à diversão (BARREIRA, 2010, 2013b). Embora o combate também possa assumir a forma de duelo, esta não foi abordada no presente trabalho.

Devido à sua constituição como dança e luta, mas também ao fato de estar sujeita ao predomínio de vivências de hostilidade que, eventualmente, chegam a concretizar brigas, aqueles três fenômenos dizem respeito à capoeira. Contemplando os possíveis valores que os capoeiristas podem mobilizar em sua prática, é importante compreender qual o sentido e consequência que se emprega ao combate. Desta maneira esta pesquisa teve por objetivo identificar e compreender, por meio de relatos de praticantes, como se dão as experiências vividas pelos capoeiristas no trânsito psicológico entre brincadeira, luta e briga.

\section{BASES TEÓRICAS}

A aplicação da fenomenologia clássica a objetos culturais - como quer uma arqueologia fenomenológica das culturas (ALES BELLO; 1998; BARREIRA, 2013a) - é a perspectiva adotada neste trabalho. $A$ abordagem de seu objeto, portanto, prescinde deliberadamente de conceitos previamente estabelecidos. A exclusão de circuito de pré-concepções visa deixar 0 próprio fenômeno emergir tecendo os contornos que o constituem, o que revela o objeto pela ótica da consciência intencional. Centrando-se na experiência do sujeito da cultura, no caso da capoeira, a apreensão direta do fenômeno em sua espessura vivida nem faz a projeção de 
uma teoria sobre o objeto, nem se vale do objeto para corroborar uma teoria prévia. A prática fenomenológica não tem nada a dizer ou a avançar teoricamente sobre a capoeira. Ao contrário, colocando-se à escuta de sua experiência, quer dar a ver seu sentido próprio, explicitando aquilo que se mostra nos limites em que se mostra.

A prévia análise fenomenológica da experiência de combate corpo a corpo (BARREIRA, 2010, 2013b) possibilita antecipar as fronteiras experienciais que diferenciam os fenômenos combativos denominados duelo, luta, briga e brincadeira de lutar. Essa antecipação, entretanto, não equivale a partir dessas categorias para apreender os fenômenos, mas equivale a ir ao encontro das experiências propriamente ditas conforme vividas na capoeira, independentemente de sua denominação e representação categorial. O recorte quer apreender apenas as três últimas experiências - antecipadas com o sentido de luta, briga e brincadeira a ser preenchido pelas vivências dos praticantes - e a maneira como ocorrem as passagens entre uma e outra no interior da experiência combativa. Foram excluídos, portanto, motivos anteriores ou estranhos ao próprio desenrolar do jogo, como rivalidades prévias e questões de honra que engendram o duelo. Tratando-se de uma investigação fenomenológica em psicologia, ou de uma psicologia fenomenológica, as entrevistas seguiram o referencial exposto por Ranieri e Barreira (2010) e Barreira e Ranieri (2013).

\section{DECISÕES METODOLÓGICAS}

Utilizou-se a entrevista fenomenológica com a intenção de acessar as experiências de combate entre capoeiristas. Ranieri e Barreira (2010) e Barreira e Ranieri (2013) delineiam os critérios científico-metodológicos de entrevistas nesta perspectiva, desde sua fundamentação epistêmica no fenômeno da empatia até a análise dos relatos.

A amostra intencional foi composta por dez capoeiristas cujos tempos de prática variam de cinco a 30 anos, inserindo-se em grupos de academias e projetos sociais de diferentes cidades do interior de São Paulo. Todavia, para efeito de descrição das experiências vividas ora almejadas, essa diversificação entre os sujeitos se mostrou irrelevante, uma vez que a redução fenomenológica pretendida não aborda as maneiras pelas quais se lida com as situações, mas os elementos essenciais que constituem os fenômenos e as passagens de um a outro. A quantidade de entrevistas foi limitada com base na saturação, isto é, quando houve repetição sistemática dos sentidos expressos nos relatos. As entrevistas foram gravadas e transcritas para, posteriormente, realizarem-se as reduções fenomenológicas e o cruzamento intencional, com o intuito de explicitar o sentido do que é vivido pelos capoeiristas no momento do combate.

As identidades dos capoeiristas foram resguardadas. Por esse motivo, valeu-se de pseudônimos atribuídos aos depoentes a fim de evitar sua identificação. As entrevistas foram realizadas após a assinatura de um termo de consentimento livre e esclarecido, atendendo aos requerimentos éticos para este tipo de pesquisa.

A entrevista semiestruturada seguiu o roteiro abaixo, direcionando cada entrevistado a contactar e expressar as experiências próprias:

Quando você está praticando capoeira, como você experiencia a luta?

Como é a experiência de brincar e jogar capoeira para você?

Você já passou por uma situação em que você e/ou seu adversário se descontrolaram? 


\section{ANÁLISES E RESULTADOS}

Ao acessar e cruzar as experiências dos entrevistados foram identificadas cinco categorias que equivalem às vivências dos capoeiristas. As três primeiras mostram o sentido de cada fenômeno combativo na especificidade da capoeira. As duas últimas expressam a transição por entre suas fronteiras. Na especificidade da capoeira, brincadeira, luta e briga se identificam respectivamente como: Alegria de Jogar, Jogo da Cumplicidade e A Negação do Jogo. Jogo de Prudências e Jogo Duro referem e explicitam a transição entre aqueles fenômenos combativos.

\subsection{Alegria de Jogar}

Equivalendo ao brincar de lutar, esta experiência é marcada por momentos descontraídos, onde os capoeiristas se preocupam menos com a efetividade das técnicas e combatem intercambiando um momento de maior entrega. Como explicitado no relato do entrevistado:

Você fica um pouco mais relaxado [...] fica até um pouquinho displicente também [...] faz uma defesa de uma maneira um pouco mais vulnerável, às vezes faz um golpe de uma maneira um pouco mais vulnerável. [...] Você se movimenta simplesmente pelo prazer de se movimentar. (Mestre Mola).

Nos relatos a brincadeira se mostrou com mais frequência, principalmente no jogo entre capoeiristas mais experientes com iniciantes. No caso, os adultos brincam mais com as crianças e este fato pode ser entendido pelas diferenças técnicas e físicas existentes entre as partes, onde o adulto se sente mais "livre" ao fazer os movimentos diante de uma criança. O excerto abaixo explicita essa lógica:

A gente relaxa quando está jogando com as crianças, né? Que a gente vê que não tem nem um problema assim [...] Não tem o perigo de levar um contra golpe [...] porque a criança não tem força para te derrubar, né... Então, aí sim dá para jogar mais descontraído, sabe, dá para brincar. (Zé Pequeno).

Também se vê a possibilidade de acontecer a brincadeira em um combate envolvendo jovens e adultos. Todavia, diferentemente do jogo com uma criança, nesta situação as condições físicas e, possivelmente, técnicas são mais próximas, deixando os combatentes mais cautelosos em seus movimentos, não se abrindo tanto para possíveis contra-ataques. Esta cautela pode corresponder a um impedimento do desenrolar da brincadeira. $\mathrm{O}$ excerto abaixo evidencia isso:

Agora nessa questão do adolescente e jovem, já ficou um pouco difícil você fazer muita brincadeira na roda. Você não sabe o que ele está pensando [...] então você tem que estar mais esperto na questão do adulto. (Mestre Passarinho).

Trata-se, portanto, de outro elemento que não a condição física para o enfrentamento, determinando a descontração própria da Alegria de Jogar, a confiança e cumplicidade lúdica, quase displicente entre os capoeiristas.

\subsection{Jogo da cumplicidade}

A luta na capoeira é caracterizada pelo seu universo contextual, que é constituído por elementos como a instrumentação, a música, o ritmo, a camaradagem entre os capoeiristas, 0 respeito, a continuidade da luta e a consciência de limite. 
Quando estão lutando, os capoeiristas seguem o ritmo e a intenção que as músicas induzem. As músicas resguardam o sentido que é empregado na luta, ora indicando que se deve fazer uma luta mais dura, ora uma luta mais serena. 0 trecho ilustra esta condição:

O berimbau é o que comanda a roda! [...] o ritmo que está sendo tocado é o que você tem que jogar [...] na hora uma vadiagem que é uma brincadeira, um envolvimento deste tipo, você tem que entrar no ritmo e fazer, se o berimbau pede um jogo duro, vai fazer um jogo duro. (Mestre Grilo).

A luta é "cercada" pela identificação do outro como pessoa. O adversário é visto como outro ser, merecedor de respeito, motivo pelo qual é preciso constantemente ficar atento aos limites do seu companheiro de luta, tentando manter a cumplicidade do combate. Como identificados nestes trechos:

Então, eu o tempo todo eu enxergo o outro que está na roda comigo como outro capoeirista, portanto não meu inimigo. (Macaco Velho).

$[\ldots]$

A capoeira tem golpe que você vai acertar, é um jogo de contato, mas desde que você respeite o seu oponente, você consegue controlar o seu golpe. (Bambu).

O desafio também é um elemento determinante na luta da capoeira, aparecendo especificamente como uma forma de "teste" onde, ao jogar com seus adversários, os capoeiristas colocam à prova suas habilidades. Nestas condições os combatentes procuram dificultar o jogo do outro, num desafio mútuo e deliberado. Como explicitado no trecho: "Acertando ou queda, levantando, o jogo continua naturalmente [...] não foi na maldade que ele me acertou, foi para... um desafiar o outro dentro da camaradagem" (Mestre Olho de Gato).

Um dos diferenciais mais marcantes em relação a outras práticas de combate é que, na capoeira, não se busca finalização, ela não tem entre suas metas acabar o quanto antes com o confronto. Seu objetivo permanece na fluidez do jogo, na continuidade. Assim como explicitado neste excerto:

Você vê que ele faz um jogo mais limpo, um jogo realmente não procura querer é... mostrar nada para você, ou te dar um pontapé para acabar logo com o jogo, é uma pessoa que está ali e você sente que quer fazer essa troca de experiência, né... e é uma pessoa que dá continuidade mesmo. (Mestre Tigre).

Assim, é como um jogo de ações e reações, entre uma constante percepção de ações corporais e sentidos empregados nos movimentos dos capoeiristas que a capoeira se mostra. Esta condição é desvelada neste excerto: "[...] capoeira é um jogo de perguntas e respostas. Se o cara te pergunta, você tem que saber responder, né? Cara, e quando você perguntar para ele, também ele vai ter que se esquivar" (Zé Pequeno).

\subsection{A negação do jogo}

Corresponde à briga na capoeira. Experiência que passa pelo desrespeito, sem a apreensão do outro como pessoa, com os combatentes buscando a qualquer custo anula- 
rem-se sem cumplicidade. A briga busca a oportunidade de encerrar o combate infligindo uma derrota física e moral ao oponente. Como pode ser visto adiante:

Briga já é quando o outro quer ferir o outro, né, um quer ferir o outro, aí não tem mais o respeito. (Mestre Olho de Gato).

Mas muitos tentam realmente é destruir, né... e aí parou a roda e se não para a roda, os mestres vão, organizam e separam e não deixa jogar. (Macaco Velho).

No apagamento dos limites da luta há uma intenção de machucar, ferir o outro e destruir o jogo. Desta maneira, os praticantes saem do que seria o contexto da capoeira e, muitas vezes, até se utilizam de técnicas estranhas à capoeira, fazendo movimentos oriundos de outras artes marciais, ou qualquer tipo de golpe, só para atingir seu adversário. Nota-se isso nos relatos:

A partir do momento que o outro quer ferir o outro, aí já não é comum mais, né... Aí torna agressão, torna-se briga, está fora do contexto da capoeira [...] começa a agarrar, agarrar cabelo, agarrar e aí já não é mais capoeira. (Mestre Olho de Gato).

Então você vê muitos capoeiristas, muitos capoeiristas bons, bons capoeiristas que, na roda, usam movimentos de outras lutas. (Macaco Velho).

Portanto, a briga comparece como um descontrole que foge do horizonte intencional do que seria a luta na capoeira, deixando de lado todo o universo da "capoeiragem": não se busca mais seguir o ritmo da música, não se vê mais o "comandante da roda", o berimbau. $\mathrm{O}$ horizonte motivacional dos combatentes limita-se a diminuir 0 adversário àquele momento hostil, visando anulá-lo numa negação do jogo.

\subsection{Jogo de prudências}

Correspondente à transição entre brincadeira e luta, aqui se intensifica a dosagem de prudência, ou seja, durante o enfrentamento, os capoeiristas permanecem cautelosos. Ora fazem movimentos mais soltos e despreocupados, correspondendo à brincadeira, ora aumentam o zelo defensivo e a intensidade dos movimentos de ataque, conforme a troca intercorporal. A fronteira destes dois fenômenos acontece nesta oscilação entre um jogo mais solto e um jogo mais "formal". Como salientado no excerto:

Se você perceber que o cara tem malícia e vai querer chegar em um certo ponto ele pode querer desta brincadeira, ele citar um momento de... sei lá! De uma violência de um tombo dele, mas não, aí você tem que colocar a sua brincadeira também, né... e rebater com o que ele está fazendo. [...] Você vai entrar na brincadeira do cara e o cara entra na sua, né... mas aí tudo tem o seu limite, na hora que essa brincadeira chegou em um certo ponto, volta um jogo normal, um jogo fechado mesmo. (Mestre Grilo).

Nesse relato percebe-se que é possível sustentar a experiência de brincadeira, no caso, colocando sua posição diante de seu adversário, contribuindo para a fluidez do jogo de maior desprendimento. Porém, no decorrer do combate, há um limite pelo qual, da brincadeira, inicia-se a passagem para a luta. Esse limite parece ser marcado por um combate tecnicamente mais exigente, fechando as aberturas da brincadeira que faziam o jogo mais solto e, ao 
mesmo tempo, vulnerabilizando os capoeiristas frente a qualquer ataque. Começa a haver um jogo de prudências quando os praticantes sentem ser necessária maior cautela.

O excerto a seguir explicita a percepção do capoeirista sobre o seu adversário, compreendendo a forma na qual o combate deve se seguir:

Se a gente começar de uma forma mais aberta ou faço uma 'estrela', [...] você está abrindo o corpo para o cara, ta abrindo assim: 'eu não quero confronto'. [...] Vai fazer um movimento que não é para acertar mesmo e o cara vai perceber: 'Pó! O cara não está com maldade'. Aí vice-versa, a mesma coisa. Aí acontece uma brincadeira legal! Agora se você finta fazer um 'aú', o cara já vira para te dar uma 'calcanheira' na boca, ele finta já! Você não poderia pegar, é sinal que eu já não posso mais fazer isso, o cara já não quer brincar. (Mestre Olho de Gato).

Nesse relato nota-se que a percepção de aumento da dosagem de riscos no combate leva ao processo de transição entre brincadeira e luta. Se o adversário se apresenta de maneira mais incisiva, com ataques e defesas mais precisas, intensifica-se o risco. Sente-se a transição que equivale à mudança de características do jogo para luta, cujo diferencial fundamental é uma disputa que se instala num desafio crescente.

\subsection{Jogo duro:}

A fronteira entre a luta e a briga consiste num processo que oscila entre o aumento ou contenção da intensidade e da agressividade no combate. Quanto mais agressivo e descontrolado o combate, mais tende a se aproximar do que seria a briga, um combate francamente hostil. Contraposta a essa situação, o confronto que ocorre, ainda que com agressividade, sem hostilidade e com maior controle, penderia para o interior das fronteiras da luta. A transição percorre exatamente os limites que cerceiam os fenômenos de briga e luta.

Na capoeira essa transição se mostra como o que pode ser chamado de "jogo mais duro", onde os movimentos são mais rápidos e perigosos, os capoeiristas ficam mais atentos, mais fechados à brincadeira, mais agressivos, na berlinda de fugir do contexto da capoeira. 0 relato salienta essa condição:

Foi um jogo mais duro, cada um... o mestre fala que: um testou o outro, né... Cada um se testou, mas partiu, saiu um pouquinho da capoeira. Os caras foram lá e cortaram, os caras respeitaram o berimbau, respeitam o mestre que foi lá e para o jogo, se cumprimentaram e beleza. (Mestre Olho de Gato).

O trânsito em questão pode se dar também pela oscilação entre controle e descontrole, marcados pela confiança e sua perda durante o combate e mesmo pela falta de técnica dos combatentes. A confiança e o controle parecem ligados à relação que o capoeirista estabelece com suas habilidades na capoeira diante de determinada situação de tensão. Ou seja, se o capoeirista se sente confiante com suas possibilidades de movimento na luta, provavelmente tenha mais condições de manter o controle, realizando movimentos da capoeira e respeitando os limites do contexto da modalidade. Por outro lado, uma pessoa que não sinta tanta confiança em suas habilidades tenderia a se descontrolar com mais facilidade sob pressão, podendo usar recursos que fujam ao universo da capoeira, frustrando-se e, tomado pela hostilidade que acompanha a frustração, passando eventualmente à briga. $O$ seguinte excerto mostra essa condição:

Você vai... [...] pra mim, corre o risco de sair fora da... do universo da capoeira [...] bons capoeiristas que na roda usam movimentos de outras lutas. [...] Eu estimulo 
as pessoas, os alunos, os capoeiristas que treinam comigo a usar só a capoeira a explorar a capoeira, por exemplo: se eu sinto alguma deficiência com alguém em um jogo eu tento procurar uma coisa dentro da capoeira. (Macaco Velho).

Quando há intensificação do combate, um capoeirista pode não se sentir seguro com os recursos da capoeira e se utilizar de técnicas estranhas à modalidade. Trata-se de usar meios inauditos, inesperados no contexto da capoeira e, portanto, de certa forma, extravia-se a equivalência de condições técnicas no interior da qual a disputa de capoeira se coloca. Esse extravio da equivalência de possibilidades de ação entre os jogadores impõe um fator de diferenciação na luta que é estranho à capoeira. Trata-se de um passo que se arrisca a ir em direção à briga, já que tende a frustrar o jogo do outro por um meio que pode ser sentido como traiçoeiro, uma deslealdade que mereça revide.

Esse processo da passagem da experiência de luta para briga é atravessado pela intensificação do combate. Como se nota neste relato, quando estão jogando, os capoeiristas percebem as mudanças na cumplicidade do desafio corporal e agem conforme a situação:

\footnotetext{
E aí ele achou... tipo, que eu estava desrespeitando ele e ele também já mudou a característica do jogo dele. E aí, então, o sangue subiu também e a gente perdeu o controle... e mudou a característica do jogo dele e eu também já meio que senti pressionado, assim, né... e tal, e também já mudei a característica do meu jogo [...]. Onde tinha objetivo mais claro, os movimentos eram mais pontuais, mas incisivos... Foi assim, ninguém se machucou assim, só foi alguns chutes aqui outros ali, mas nada demais assim... (Mestre Mola).
}

Esse excerto mostra o momento em que ocorre a transição. Exteriormente, nem sempre é possível saber precisamente se os combatentes estão vivendo uma luta ou uma briga, já que se inicia o processo de intensificação sem que se fuja do contexto da capoeira. Portanto, se objetivamente as ações ainda se colocam como luta, sustentando a capoeira e o controle de suas técnicas, subjetivamente pode-se apreender que a intensificação correspondeu a uma perda de respeito e de controle menos próprios à luta do que à briga.

O "jogo duro" se caracteriza, sobretudo, como um jogo com dosagens de intensificação e brandura, transitando nas fronteiras da subjetividade combativa, podendo se encaminhar objetivamente para a coisificação da briga ou permanecer no respeito empregado nas ações da luta.

\section{DISCUSSÃO}

Em consonância com Valério e Barreira (2012), constatou-se a estruturação do combate na capoeira pela cumplicidade e pelo acordo corporal. Notou-se que a variação, ou perda do acordo corporal e da cumplicidade, corresponde à tendência para mudança das formas de combater. Essa modificação comparece como um processo de oscilação da intensidade, eventualmente levando às transições entre brincadeira, luta e briga.

Mas como se deve compreender a questão da intensidade e sua percepção na experiência combativa? Certamente, quando esta atua na transição entre os diferentes fenômenos combativos, não se trata apenas de intensificação física. Isto deve ser afirmado porque o capoeirista - e o combatente em geral - não a percebe assim. Ou seja, o sujeito do combate não percebe o aumento da intensidade como meramente físico, como um recorte de um aspecto da experiência, mas como uma totalidade de pressão, como intensidade dinâmica 
na troca combativa, concebendo-se, portanto, como unidade abrangente que toma e define a experiência que se desenvolve. Trata-se de uma experiência direta, uma percepção que não é mediada por um retorno sobre si mesma, isto é, não é reflexiva, não envolve a necessidade de um dar-se conta do que se vive e, a partir disso, de uma deliberação racional para a ação a ser realizada. A experiência em questão é, antes de tudo, afetiva, acontecendo e tomando 0 sujeito desta, que é uma experiência pré-reflexiva, definindo-se como vivência eminentemente corporal. A depender da qualidade dos afetos que tomam e preenchem os sujeitos do combate, testemunha-se uma briga, um duelo, uma brincadeira ou uma luta (BARREIRA, 2013a).

Portanto, nessa experiência, que não é irracional, não há qualquer primazia ou privilégio de uma razão instrumental ou analítica - o que a situaria num registro reflexivo. Em outras palavras, durante a experiência de combate, o sentido do enfrentamento não se coloca primeiramente como meio para se chegar a outra coisa, outro fim - este fato diminui a importância da razão instrumental. Tampouco se faz por um processo cognitivo de decomposição das dimensões física e psicológico-moral da experiência, constatação que afasta a razão analítica da experiência primária de combate. A razão do combate - e daí sua racionalidade correspondente (BARREIRA, 2013a) - se define no solo da intensidade do intercâmbio das ações. Isso não significa que a intensidade das ações esteja isolada em si mesma, isto é, se defina exclusivamente pelo que se passa durante o combate. Se é certamente no registro dessa intensidade que a qualidade do combate se define, deve-se conferir que as motivações para o desenrolar da intensidade podem advir de momentos estranhos à duração do combate em si, ou seja, estranhos ao que se passa exclusivamente entre seu início e seu fim. Ainda assim, essas motivações não seriam estranhas à intensidade, comparecendo nela mesma de modo a qualificar como a intensidade se apresenta. Esse seria bem o caso de um duelo/desafio, combate consentido entre os oponentes, cuja motivação é, necessariamente, uma questão de honra (BARREIRA, 2013a), possibilidade combativa excluída no recorte desta investigação. Trata-se, num caso como esse, bem como no caso de uma briga, de examinar os motivos de cada acontecimento para compreender seu sentido específico. Diferentes autores - Mello et al. (2010) e Radicchi, Falcão e Kunz (2011) - já apontaram a rivalidade entre grupos de capoeiristas como motivo para os episódios de violência predominantes em seu meio social. Fenomenologicamente, deve-se constatar, entretanto, que, se a experiência de aumento da intensidade é essencial para a briga, comportando inclusive a eventual rivalidade em seu interior, a rivalidade entre grupos não é essencial para ela, mas uma de suas possíveis motivações.

Outro aspecto fundamental para se compreender a maneira como a variação na intensidade do combate o qualifica é, de fato, o lutador, o sujeito do combate. Como o sujeito vive 0 combate? Quais as suas condições para o enfrentamento?

Essas perguntas não focam mais os motivos que ensejam as diferentes formas de combater - duelo/desafio, briga, brincadeira e luta. Assim como essas formas de combate (objeto) se definem primeiramente pela qualidade da intensidade pré-reflexiva que as constitui, o protagonista do combate (sujeito) é afetado e mobilizado pela mesma qualidade. Vale mencionar, embora isso não possa ser mais bem explorado aqui, que em chave fenomenológica o vértice afetivo a partir do qual emergem os pólos objetivos e subjetivos na base de qualquer experiência encontra relevantes conceituações, primeiro junto a Edmund Husserl, secundariamente junto a Maurice Merleau-Ponty. Husserl, o filósofo que funda a fenomenologia, denominará essa dimensão material vivente por hilética, recorrendo à terminologia grega (BARREIRA, 
2013b; ALES BELLO, 1998). Ser bruto é a denominação que Merleau-Ponty dá a essa dimensão (ALES BELLO, 2008). Reivindicar esses conceitos serve para conferir como a objetividade do combate se origina com a subjetividade do combatente em sua estrutura ontológica. Nesse caso, a universalidade das formas de combate se encontra com a relatividade do combatente, permitindo a compreensão de suas variadas configurações culturais, bem como a variação psicológica com que diferentes pessoas vivem a experiência de intensidade combativa. É no terreno dessa relatividade psicológica do sujeito do combate que as perguntas acima encontram as pistas para serem respondidas.

A relação combativa, tanto na capoeira quanto em outras lutas e artes marciais, se coloca necessariamente como um desafio em que se visa, em última instância, restringir a mobilidade do adversário e evitar ter a sua mobilidade restrita, isto é, como um desafio em que se procura superar fisicamente o outro (BARREIRA, 2013a). Há, portanto, uma relatividade intersubjetiva, ou seja, própria à dupla de combatentes em enfrentamento, que atua um incontornável papel aqui. Nos resultados isso pode ser conferido quando se atribuiu ao jogo com crianças a melhor condição para se viver a capoeira como brincadeira. As diferenças entre um adulto experiente e uma criança que aprende a capoeira se abstrairiam em níveis físicos, técnicos e psicológicos, já que a clareza entre quem é mais vulnerável está colocada, assim como a responsabilidade pela preservação das condições de jogo sem violência se estabelece, obviamente, junto ao adulto. Essas diferenças delineiam as condições gerais para o enfrentamento entre quaisquer sujeitos, tanto como aspectos decisivos para sua percepção. Os resultados a que chega García (2008) permitem ampliar essa leitura. O autor mostra como o gradual domínio prático de um lutador lhe permite progressivamente levar em consideração o outro, adotando cuidados especialmente com praticantes de nível inferior. Já os novatos possuem menor controle no momento do combate, escreve:

[...] estão posicionados nas extremidades: ou há excesso de cuidado do outro, portanto, não há quase nenhuma intensidade [...] ou não há quase nenhuma consideração, não há identificação (o indivíduo está centrado em seu próprio medo), pelo que as ações são de intensidade excessiva. (GARCÍA, 2008, p.219).

O diálogo com o trabalho de Raúl Sanchez García fortalece a compreensão assertiva de aspectos dos resultados aqui apresentados. $O$ capoeirista experiente ou, em sentido geral, o sujeito experiente de uma prática de combate, desenvolve-se como lutador à medida que "[...] vai obtendo certo domínio do conhecimento (prático), pelo que o controle sobre a atividade aumenta e o nível de perigo e medo diminui" (GARCÍA, 2008, p.219). Assim, à maneira do "jogo duro", torna-se possível "[...] realizar a atividade com uma intensidade maior, porém sem perder o controle" (GARCÍA, 2008, p.219). Mas o "jogo duro", figura expressiva do drama de uma luta que pode deslizar para a violência, equilibra-se desafiadoramente sobre uma fronteira perigosa, na medida em que o sujeito prova limites e quer expandir as linhas daquilo que é capaz, daquilo que pode realizar combativamente. Se o praticante experiente tem mais condições de controle, entretanto, nem por ser um mestre está isento do risco de perdê-lo. Diria García (2008, p. 226) que o risco de conflito hostil permanece como ideal, se toda possibilidade de desvio for encerrada.

\section{CONCLUSÃO}

Os resultados explicitam alguns sentidos da experiência humana de combater na capoeira. Foi possível identificar que o trânsito psicológico entre brincadeira, luta e briga manifesta- 
-se de maneira pré-reflexiva, numa experiência intersubjetiva, mobilizada por oscilações entre a brandura e a intensificação. Ou seja, no momento do enfrentamento, os capoeiristas podem viver uma situação de intensificação e abrandamento da luta sem antes pensarem propositalmente nesse processo, pois o jogo da capoeira acontece num fluxo de posições e percepções, ações e reações entre os oponentes, sem precisar passar pelo crivo da reflexão. Trata-se de vivências diretas, impregnadas na situação, correspondendo ao que seria a "pergunta-resposta" da capoeira enquanto luta corporal. Especialmente, as experiências de briga, no contexto das práticas de luta, e da capoeira em particular, podem se dar sem intenções deliberadas de vivenciar esse fenômeno, mas como acontecimentos do desenrolar do enfrentamento. Entretanto, reconhecer isso não significa afirmar que não existam meios de controlar a tomada hostil que marca a briga, tampouco que brigas não possam acontecer deliberadamente.

Foi possível desvelar a subjetividade correspondente à capoeira no encontro de suas fronteiras quando há emergência das vivências próprias à briga. Embora não tenha sido objeto desta investigação, as entrelinhas dos relatos permitem afirmar que capoeiristas mais experientes conseguem se posicionar em modos que favorecem a permanência do sentido do jogo. Desta maneira, confere-se que o processo de intensificação do combate pode levar às fronteiras que 0 delineiam tornando perceptíveis junto aos praticantes os limites a partir dos quais 0 sentido da capoeira tende à distorção.

Todavia, considerando as experiências relatadas, deve-se salientar também que vivenciar combates mais intensos, até mesmo combates que tangem à briga, permite aos sujeitos do combate aprenderem a reconhecer os seus próprios limites, dosando sua presença na luta, adquirindo uma experiência que potencializa as condições para equilibrar as divergências entre controle e descontrole, em privilégio do primeiro, cultivando-se as condições existenciais para o autodomínio. Esse pode ser um aspecto educativo do "jogo duro", que permite o desenvolvimento dos combatentes por via da percepção em primeira pessoa dos limites da capoeira, dos limites do adversário e, principalmente, de seus próprios limites. Trata-se de dar-se conta de que o jogo que permanece somente no abrandamento lúdico, indulgente, não é capaz de estimular as mudanças e os desenvolvimentos colocados pelo desafio da luta intensificada. Assim, na capoeira, lutar se coloca como desafio à autoindulgência predominante na brincadeira. Do contrário, isto é, no caso de haver apenas a brincadeira, o resultado esperado pode ser 0 despreparo dos praticantes para um enfrentamento mais intenso, o que os deixa mais sujeitos ao descontrole. Convergindo com as reflexões de Barreira (2013b), a luta é uma constante de aperfeiçoamento e conhecimento de si, possibilitando uma ação ética no combate e no mundo da vida: procurar manter o horizonte motivacional da luta é permanecer na essência dessa experiência, desenvolver-se como lutador.

Luta, dança, jogo, brincadeira embalada pela musicalidade, a capoeira é multifacetada e, como tal, sua experiência é eminentemente ambígua. As distinções aqui empreendidas, a exemplo de Barreira (2013b), obedecem ao propósito da redução fenomenológica. Distinguir essas formas combativas possibilita inclusive apreender o que há de intencionalmente ambíguo na capoeira em momentos em que luta, brincadeira e briga parecem conviver se sucedendo e até se sobrepondo. No contexto prático, o professor ou mestre de capoeira age como eixo determinante para o equilíbrio da experiência de combate, já que lhe cabe reconhecer o que predomina em meio às ambiguidades do confronto e intervir caso ocorra a perda do sentido da capoeira, bem como permitir a fluidez da luta quando há um "jogo duro" em que se sustenta seu 
sentido, resguardando experiências que podem passar desde a brincadeira com despreocupação displicente até as vivências que tangenciam a briga, embora sem concretizá-la. Sempre, porém, cabe-Ihe o papel de guardião de uma atmosfera em que as vivências predominantes não se destinem a perder de vista os combatentes como pessoas merecedoras de respeito e cuidado, pessoas cujo desenvolvimento combativo deve corresponder, por sua vez, à incorporação sensível de deveres que se colocam reciprocamente como atitude de cuidado com relação aos outros.

\section{REFERÊNCIAS}

ALES BELLO, Angela. Culturas e Religiões: uma leitura fenomenológica. Tradução A. Angonese. Bauru: EDUSC, 1998. 199 p.

ALES BELLO, Angela. Essere grezzo e hyletica fenomenologica: I' eredità filosofica di “II visibile e I' invisibile". Memorandum, Belo Horizonte, v. 14, n. 2, p. 62-78, 2008. Disponível em: <http://www. fafich.ufmg.br/ memorandum/a14/alesbello06.htm>. Acesso em: 15 de out. 2013.

BARREIRA, Cristiano Roque Antunes. Fenomenologia da luta corporal e da arte marcial. In: SEMINÁRIO INTERNACIONAL DE PESQUISA E ESTUDOS QUALITATIVOS (SIPEQ), 4. 2010.

Anais .... Rio Claro, 2010. p. 1-8. Disponível em: <http://www.sepq.org.br/IVsipeq/anais/artigos/OBS3. pdf>. Acesso em: 15 mar. 2012.

BARREIRA, Cristiano Roque Antunes. Fenomenologia do combate: da ética da luta à luta pela vida ética. In: MAHFOUD, Miguel; MASSIMI, Marina. (Ed.). Edith Stein e a Psicologia: Teoria e Pesquisa. Belo Horizonte: ArteSã, 2013b. cap. 16, p. 413-447.

BARREIRA, Cristiano Roque Antunes. 0 sentido do karate-do: faces históricas, psicológicas e fenomenológicas. Rio de Janeiro: E-papers, 2013a. 278 p.

BARREIRA, Cristiano Roque Antunes. Os valores na pedagogia das lutas, artes marciais e modalidades esportivas de combate. In: FRANCHINI, Emerson.; VECCHIO, Fabrício Boscolo Del'. (Ed). Reflexões e Propostas de programas. São Paulo: Scortecci, 2012. cap. 2, p. 28-46.

BARREIRA, Cristiano Roque Antunes; RANIERI, Leandro Penna. Aplicação de contribuições de Edith Stein à sistematização de pesquisa fenomenológica em psicologia: a entrevista como fonte de acesso às vivências. In: MAHFOUD, Miguel; MASSIMI, Marina. (Ed.). Edith Stein e a Psicologia: Teoria e Pesquisa. Belo Horizonte: ArteSã, 2013. cap. 17, p. 449-466.

BERTAZZOLI, Breno Fiori; ALVES, Danilo de Almeida; AMARAL, Silvia Cristina Franco. Uma Abordagem Pedagógica para a Capoeira. Movimento, Porto Alegre, v. 14, n. 2, p. 207-229, 2008.

GARCÍA, Raúl Sánchez. Análisis etnometodológico sobre el dinamismo del habitus en Bourdieu y Elias dentro del desarrollo de actividades corporales. Revista Española de Investigaciones Sociológicas (Reis), Madrid, v.2, n. 124, p. 209-231, 2008.

HÉBERT, Jacques (Ed.). Arts Martiaux, sports de combat et interventions psychosociales. Québec: Presses Universitaires du Québec, 2011. 344 p.

MELLO, André da Silva et al. A construção da rivalidade e da violência entre os grupos de capoeira de Piúma, ES. Pensar a Prática, Goiânia, v. 13, n. 2, p. 117, 2010.

RADICCHI, Marcelo Rocha; FALCÃO José Luiz Cirqueira; KUNZ, Elenor. Excertos ácidos: Um ensaio sobre a capoeira a partir de algumas obras da chamada Teoria Crítica. RELEM Revista Eletrônica Mutações, Parintins, v. 2, n. 2, p. 1-12, 2011. Disponível em: <http://www.relem.info/edicoes/ed2/art2. pdf >. Acesso em: 1‥ mar. 2013.

RANIERI, Leandro Penna; BARREIRA, Cristiano Roque Antunes. A entrevista fenomenológica. In: 
SEMINÁRIO INTERNACIONAL DE PESQUISA E ESTUDOS QUALITATIVOS (SIPEQ), 4. Rio Claro. Anais... Rio Claro: UNESP, 2010. p. 1-8, Disponível em: <http://www.sepq.org.br/IVsipeq/anais/ artigos/46.pdf>. Acesso em: 15 mar. 2012.

REIS, André Luiz Teixeira. Capoeira Saúde \& Bem-estar Social. 2. ed. Brasília, DF: Thesaurus, 2010. $205 \mathrm{p}$.

TRUSZ, Rodrigo Augusto; NUNES, Alexandre Velly. A evolução dos esportes de combate no currículo do Curso de Educação Física da UFRGS. Movimento, Porto Alegre, v.13, n. 1, p.179-204, 2007.

VALÉRIO, Pedro Henrique Martins; BARREIRA, Cristiano Roque Antunes. A cultura capoeira como fonte pedagógica da prática capoeira. In: FRANCHINI, Emerson; VECCHIO, Fabrício Boscolo Del'. (Ed). Reflexões e Propostas de programas. São Paulo: Scortecci, 2012. cap. 4, p. 62-73. 
Apoio: Pró-Reitoria de Pesquisa da Universidade de São Paulo

(J) Movimento, Porto Alegre, v. 21, n. 1, p. 125-138, jan./mar. de 2015. 